\title{
Subacute Arsenic Neuropathy: Clinical and Electrophysiological Observations
}

\author{
Ashraf V. Valappil ${ }^{1} \quad$ Abraham Mammen² \\ ${ }^{1}$ Department of Neurology, Meitra Hospital, Kozhikode, Kerala, \\ India \\ 2Department of Pediatric Surgery, Malabar Institute of Medical \\ Sciences, Kozhikode, Kerala, India
}

\begin{abstract}
Address for correspondence Ashraf V. Valappil, DM, Department of Neurology, Meitra Hospital, Edakkad P.O., Kozhikode 673004, Kerala, India (e-mail: drvvashraf@hotmail.com).
\end{abstract}

\begin{abstract}
Keywords

- arsenic intoxication

- peripheral neuropathy

- Siddha medication

We report a patient who developed subacute peripheral neuropathy following ingestion of a traditional medicine for obesity. A 9-year-old girl who had a residual equinus varus deformity and sphincter disturbance due to pelvic ganglioneuroma presented with subacute sensorimotor peripheral neuropathy of 2 weeks duration. Her symptoms started 3 weeks after she started taking a locally made traditional medicine for obesity. She had no other systemic features of arsenic toxicity. She had Mee's lines on her nails and high serum arsenic levels and 24-hour urine levels confirmed the diagnosis of arsenic neuropathy. Nerve conduction study on admission demonstrated axonal sensorimotor neuropathy with slowed conduction velocity. She was not given any specific treatment and recovery was slow. At 18 months, she showed complete recovery and electrodiagnostic parameters returned to normal values. Arsenic is a known ingredient of many Indian ethnic remedies and possibility of arsenic neuropathy should be thought of in patients presenting with acute or sub-acute peripheral neuropathy of unknown etiology.
\end{abstract}

\section{Introduction}

The most frequent neurological complication of inorganic arsenic intoxication is distal symmetrical polyneuropathy that may appear subacutely within days of massive intoxication or may develop insidiously after chronic environmental or industrial exposure. ${ }^{1}$ A chronic exposure to low-level arsenic may cause distal axonopathy, predominantly sensory polyneuropathy, that is not preceded by multiorgan involvement. ${ }^{2}$ Arsenic and mercurial compounds are known ingredients of the Indian ethnic remedies. ${ }^{3}$ These medicines are prescribed by practitioners of Ayurveda, Unani, Siddha, and other indigenous systems of Indian medicines for various diseases. We report a patient who developed subacute peripheral neuropathy following ingestion of traditional "Siddha" medicine for obesity. The serial electrophysiological findings and outcome are discussed here.

\section{Case Report}

A 9-year-old girl, who had a residual equinovarus deformity and sphincter disturbance due to pelvic ganglioneuroma, presented with progressive weakness and numbness of the upper and lower limbs for a duration of 2 weeks. The onset was insidious and started in the lower limbs, which later progressed to involve the upper limbs. She had an acute diarrheal disease and few episodes of vomiting 1 week prior to the onset of these symptoms. These symptoms were relieved within 2 days after administration of medications for symptomatic improvement. Four years earlier, the patient underwent surgery twice for the pelvic ganglioneuroma.

Three weeks prior to the admission, the patient took a Siddha medicine (powder form) for obesity. On examination, she had Mees' lines over the nails of both the upper and lower limbs ( - Fig. 1). The preexisting equinovarus deformity was 


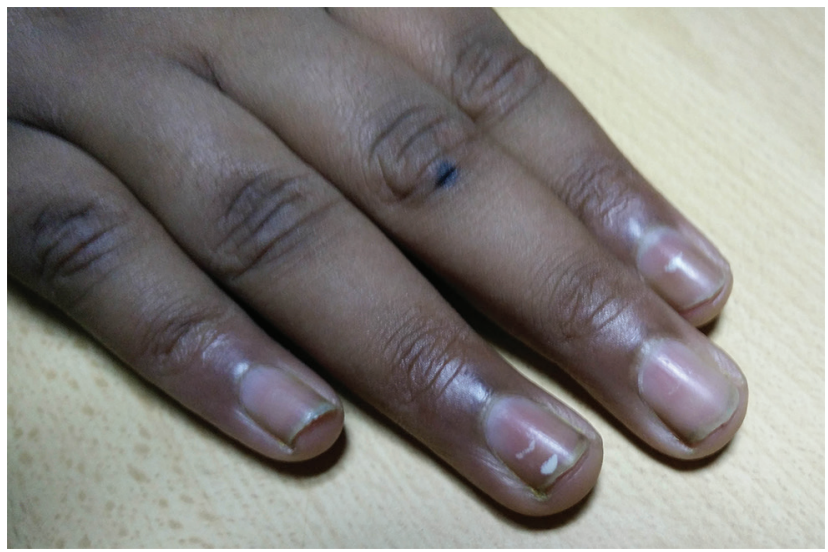

Fig. 1 Fingernails showing Mees' lines.

present in both the lower limbs. The power of the muscles of the upper limbs was as follows: shoulder and elbow, fourfifths; wrist extensors, two-fifths; wrist flexors, four-fifths; finger extensors, two-fifths; and finger flexors, four-fifths. The power of the muscles of the lower limbs was as follows: hip, four-fifths; knee, three-fifths; ankle dorsiflexors, onefifth; and plantar flexors, three-fifths (ankle contracture). The deep tendon reflexes were all absent. There was graded distal sensory impairment of both the feet and hands (glove and stocking pattern). As she had a previous history of lumbosacral root involvement due to spinal canal extension of pelvic ganglioneuroma, an initial magnetic resonance imaging of the spine and pelvis was performed to rule out any recurrence. The results of hemogram, liver, and renal function tests were within normal limits.

The nerve conduction study revealed nonstimulatable median, radial, common peroneal, and sural nerves. The ulnar and posterior tibial nerves showed markedly reduced compound muscle action potential amplitude with low con-

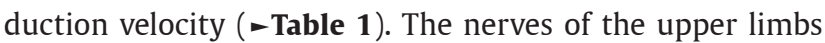
were not uniformly involved, and the median and radial nerves were more severely affected than the ulnar nerves. A repeat nerve conduction study performed at 3 weeks showed further deterioration of the parameters. A cerebrospinal fluid analysis revealed the following picture: protein, $49 \mathrm{mg} / \mathrm{dL}$; cells, nil; and sugar, $55 \mathrm{mg} / \mathrm{dL}$. The serum arsenic level was $29.3 \mu \mathrm{g} / \mathrm{L}$ (normal: $0.4-11 \mu \mathrm{g} / \mathrm{L}$ ), and the urinary arsenic level was $323 \mu \mathrm{g} / \mathrm{L}$ (normal: < $35 \mu \mathrm{g} / \mathrm{L}$ ). On the basis of the history of intake of indigenous medicine and the presence of raised serum and urinary levels of arsenic, a diagnosis of subacute arsenic neuropathy was made. The patient was advised to stop the Siddha medication and was administered antioxidants and vitamins along with initiation of physiotherapy. She gradually recovered and the upper limb deficits fully resolved by 18 months. The nerve conduction parameters of the upper limbs became normal at 18 months.

\section{Discussion}

There are reports of arsenic and mercury toxicity following ingestion of various Indian ethnic medications. ${ }^{3,4}$ Recently,
Saper et al estimated lead, mercury, and arsenic levels in Ayurvedic medications and found that one-fifth of the medications contained at least one of these heavy metals in excess of the permissible limits. ${ }^{5}$ Siddha medicine is one of the ancient systems of medicines such as Ayurveda and Unani, and in Siddha medicine, the use of metal and minerals is predominant. It has been used for the treatment of autoimmune conditions, central nervous disorders, collagen disorders system, and rheumatoid arthritis.

Our patient presented with subacute sensorimotor neuropathy and Mees' line. The possibilities, such as acute inflammatory demyelinating polyneuropathy and nutritional neuropathies, were ruled out. For initial few days of the illness, she had only symptoms in the lower limbs, and hence, a recurrence of pelvic ganglioneuroma was suspected. The most helpful diagnostic finding of arsenic polyneuropathy was the presence of Mees' line in fingernails and toenails as observed in $80 \%$ of the cases. ${ }^{6}$ The most frequent neurological complication induced by arsenic poisoning is symmetrical sensorimotor polyneuropathy featuring more distal impairment. The most prominent electrophysiological findings are marked abnormalities in both sensory and mixed nerve conduction and moderate abnormalities in motor conduction. ${ }^{7}$ In addition to the classical presentation of chronic axonal polyneuropathy, acute or subacute demyelinating polyneuropathy commencing 1 to 3 weeks following arsenic exposure has been described. ${ }^{8}$ Our patient had severe motor and sensory axonal neuropathy with reduced conduction velocity. The nerve conduction in the lower limbs was complicated by preexisting radiculoplexopathy due to pelvic ganglioneuroma. Another interesting finding was the significant motor involvement of radial nerves, more than the median and ulnar nerves. Deterioration in the results of electrodiagnostic parameters was observed initially as compared with the results during the follow-up period at 3 weeks, although it gradually recovered and became normal by 18 months.

The diagnosis of arsenic toxicity was made by demonstrating high urinary arsenic level and increased arsenic level in the nails and hairs. Serum arsenic level estimation is less useful because of rapid clearance of arsenic. ${ }^{2}$ For acute arsenic toxicity, chelating agents such as BAL, D-penicillamine, and meso-2,3-dimercaptosuccinic acid are mainly used as treatment modalities. There is no evidence-based specific treatment for chronic arsenic toxicity. ${ }^{2}$ Our patient was treated with only vitamins and antioxidants.

Arsenic neuropathy is considered as a distal axonopathy possibly related to the binding of arsenic to dihydrolipoate, a sulfhydryl component of the pyruvate dehydrogenase complex required for the oxidation of pyruvate. ${ }^{9}$ Histological studies of peripheral nerve mostly demonstrate axonal degeneration with predominant involvement of the large myelinated fibers. Chhuttani and Chopra, from their observations of demyelination and remyelination in teased fiber preparations, suggested that segmental demyelination and axonal degeneration might be equally prominent pathological features of arsenic-induced neuropathy. ${ }^{10}$ 
Table 1 Serial electrophysiological findings

\begin{tabular}{|c|c|c|c|c|c|c|}
\hline \multirow[t]{2}{*}{ Time after exposure } & \multicolumn{2}{|c|}{5 wk } & \multicolumn{2}{|c|}{$8 w k$} & \multicolumn{2}{|r|}{$18 \mathrm{mo}$} \\
\hline & Right & Left & Right & Left & Right & Left \\
\hline \multicolumn{7}{|l|}{ Median nerve } \\
\hline Latency (ms) & \multirow[t]{3}{*}{ NR } & \multirow[t]{3}{*}{ NR } & \multirow[t]{3}{*}{ NR } & \multirow[t]{3}{*}{ NR } & 3.3 & 3.7 \\
\hline Amplitude (mA) & & & & & $11.6,9.2$ & $12.5,8.5$ \\
\hline Velocity $(\mathrm{m} / \mathrm{s})$ & & & & & 61.3 & 54.1 \\
\hline \multicolumn{7}{|l|}{ Ulnar nerve } \\
\hline Latency (ms) & 2.6 & 3.1 & \multirow[t]{3}{*}{ NR } & \multirow[t]{3}{*}{ NR } & 2.5 & 3 \\
\hline Amplitude (mA) & $3.8,3.7$ & $3.5,2.1$ & & & $19.1,16.9$ & $13.3,12.7$ \\
\hline Velocity (m/s) & 39.6 & 37 & & & 58.8 & 53.8 \\
\hline \multicolumn{7}{|l|}{ Radial nerve } \\
\hline Latency & \multirow[t]{3}{*}{ NR } & \multirow[t]{3}{*}{ NR } & \multirow[t]{3}{*}{ NR } & \multirow[t]{3}{*}{ NR } & 2.6 & 2.9 \\
\hline Amplitude & & & & & $9,7.1$ & $8.5,6.9$ \\
\hline- & & & & & $55 \mathrm{~m} / \mathrm{s}$ & 51 \\
\hline \multicolumn{7}{|l|}{ Median sensory } \\
\hline Latency (ms) & \multirow[t]{3}{*}{ NR } & & \multirow[t]{3}{*}{ NR } & & 2.8 & \\
\hline Amplitude (mV) & & & & & 29 & \\
\hline Velocity (m/s) & & & & & 49.6 & \\
\hline \multicolumn{7}{|l|}{ Ulnar sensory } \\
\hline Latency (ms) & 2.5 & 2.3 & 3 & 2.9 & 2.3 & 2.5 \\
\hline Amplitude (mV) & 10.2 & 12.5 & 6.1 & 5.8 & 22.5 & 18.5 \\
\hline Velocity $(\mathrm{m} / \mathrm{s})$ & 44 & 47.8 & 39 & 40 & 48 & 46 \\
\hline \multicolumn{7}{|l|}{ Radial sensory } \\
\hline Latency (ms) & \multirow[t]{3}{*}{ NR } & \multirow[t]{3}{*}{ NR } & \multirow[t]{3}{*}{ NR } & \multirow[t]{3}{*}{ NR } & 2.1 & 2.2 \\
\hline Amplitude (mV) & & & & & 25.1 & 19.6 \\
\hline Velocity (m/s) & & & & & 58 & 55 \\
\hline CPN & NR & & NR & & NR & \\
\hline \multicolumn{7}{|l|}{ PTN } \\
\hline Latency & 5.2 & & NR & & 5.1 & \\
\hline Amplitude (mV) & 2.0 & & & & 3.5 & \\
\hline $\mathrm{CV}(\mathrm{m} / \mathrm{s})$ & 45 & & & & 48 & \\
\hline Sural & NR & & NR & & NR & \\
\hline Superficial peroneal & NR & & NR & & NR & \\
\hline
\end{tabular}

Abbreviations: CPN, common peroneal; CV, conduction velocity; NR, no response; PTN, posterior tibial nerve.

\section{Conclusion}

We observed the following features of arsenic neuropathy: (1) subacute axonal neuropathy with slowing of conduction velocity and (2) slow but complete recovery without the requirement of any specific chelating therapy. Arsenic is a known ingredient of many Indian ethnic remedies, and these medicines are a potential source of arsenic. This possibility should be considered in patients with acute or subacute peripheral neuropathy of undetermined etiology.

\section{Funding}

None.

\section{Conflict of Interest}

None declared.

\section{References}

1 Heyman A, Pfeiffer JB Jr, Willett RW, Taylor HM. Peripheral neuropathy caused by arsenical intoxication; a study of 41 
cases with observations on the effects of $\operatorname{BAL}(2,3$, dimercapto-propanol). N Engl J Med 1956;254(9):401-409

2 Vahidnia A, van der Voet GB, de Wolff FA. Arsenic neurotoxicity--a review. Hum Exp Toxicol 2007;26(10):823-832

3 Kew J, Morris C, Aihie A, Fysh R, Jones S, Brooks D. Arsenic and mercury intoxication due to Indian ethnic remedies. BMJ 1993;306(6876):506-507

4 Khandpur S, Malhotra AK, Bhatia V, et al. Chronic arsenic toxicity from Ayurvedic medicines. Int J Dermatol 2008;47(6):618-621

5 Saper RB, Phillips RS, Sehgal A, et al. Lead, mercury, and arsenic in US- and Indian-manufactured Ayurvedic medicines sold via the Internet. JAMA 2008;300(8):915-923
6 Oh SJ. Electrophysiological profile in arsenic neuropathy. J Neurol Neurosurg Psychiatry 1991;54(12):1103-1105

7 Murphy MJ, Lyon LW, Taylor JW. Subacute arsenic neuropathy: clinical and electrophysiological observations. J Neurol Neurosurg Psychiatry 1981;44(10):896-900

8 Kim S, Takeuchi A, Kawasumi Y, Endo Y, Lee H, Kim Y. A Guillain-Barré syndrome-like neuropathy associated with arsenic exposure. J Occup Health 2012;54(4):344-347

9 Chhuttani PN, Chawla LS, Sharma TD. Arsenical neuropathy. Neurology 1967;17(3):269-274

10 Chhuttani PN, Chopra JS. Arsenic poisoning. In: Vinken PJ, Bruyn GW, eds. Hand Book of Clinical Neurology. Amsterdam: North Holland Publishing Co.;1979:199-216 